\title{
THE NATIONAL MEASUREMENT SYSTEM FOR MEDICAL ULTRASONICS
}

Paul A. Hudson

Electromagnetics Division Institute for Basic Standards Boulder, Colorado 80302 



\section{NBSIR $75-937$}

\section{THE NATIONAL MEASUREMENT SYSTEM FOR MEDICAL ULTRASONICS}

Paul A. Hudson

Electromagnetics Division Institute for Basic Standards

Boulder, Colorado 80302

February 1976

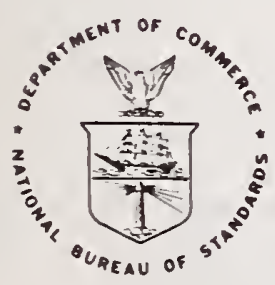

U.S. DEPARTMENT OF COMMERCE, Elliot L. Richardson, Secretary James A. Baker, III, Under Secretary Dr. Betsy Ancker-Johnson. Assistant Secretary for Science and Technology NAIIONAL BUREAU OF STANDARDS, Ernest Ambler, Acting Director 
This is one of the reports from the 1972-75 NBS Study of the National Measurement System. It deals specifically with the current structure, status and trends of the system used in this country for the measurement of physical quantities related to medical ultrasonics.

The "Concept of a National Measurement System" has been discussed by NBS authors and spokesmen for a number of years, since the publication by Dr. R. D. Huntoon of an article by that title in the October 6, 1967 issue of Science (Vol. 158, No. 3797, pages 67-71). Dr. Huntoon began his article with the following paragraph:

"Concurrently with the growth and industrialization of this nation, there has developed within it a vast, complex system of measurement which has made possible the very growth that brought the system into being. This National Measurement System (NMS) stands today as one of the key elements in a worldwide measurement system that links a 11 major nations together in a consistent, compatible network for communication and trade."

The U.S. National Measurement System is defined as comprising all of the activities and mechanisms -- intellectual and operational, technical and institutional -- used by this country to produce the physical measurement data needed to create the objective, quantifiable knowledge required by our society. This knowledge is used to describe, predict, communicate, control, and react, in many aspects of our personal and social lives, science, and technology.

Dr. Huntoon continued his discussion in 1967:

"Our National Measurement System is one of a number of mutually interacting systems within our technologically based society that form the environment in which the individual citizen must live and function. Familiar examples are the communication, transportation, educational, medical and legal systems, all of which may be included under the general heading of social systems."

"In view of the demonstrated value of the systems approach for the understanding and improvement of hardware such as computers and weapons, some of these social systems are being subjected to the same type of analysis. The National Measurement System, which evolved in this country with little formal recognition as a system, is now being examined in this way at the National Bureau of Standards (NBS) which undertook the study of the National Measurement System partly because of the all-pervasive nature and great economic importance of the nation's measurement activities, and partly because of the challenge to NBS in putting its splended new facilities to optimum use for the benefit of the nation. Such optimum use can be approached only when the National Measurement System, of which NBS is a central element, and the services it requires for effective operation are sufficiently well understood."

Over the years both before and since 1967, NBS has taken a number of approaches to the study of our national system for physical measurements. The current series of studies was initiated in 1972 by Dr. Ernest Ambler, then Dr. Huntoon's successor as Director of the NBS Institute for Basic Standards, now Acting Director of the Bureau. The reports of these studies are being presented to the public at large for the purpose of increasing national understanding, and the operational effectiveness, of our National Measurement System. They are presented as an initial or interim, not final, word on the subject. NBS welcomes contributions from all sectors of the System which can aid it in increasing its understanding of and effectiveness in supporting that System. 
EXECUTIVE SUMMARY ..........................

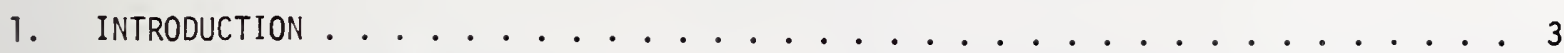

2. STRUCTURE OF THE MEASUREMENT SYSTEM ............... 3

2.1 Conceptuat system . . . . . . . . . . . . . . . 3

2.2 Basic Technical Infrastructure . . . . . . . . . . . . 5

2.2.1 Documentary Specification System ............ 5

2.2.1.1 Standardization Institutions ..........5

2.2.1.2 Survey of Voluntary (Documentary)

2.2.2.1 Standards and Recommendations $\ldots \ldots \ldots \ldots 67$

2.2 .2 .2 The Instrumentation Industry ........

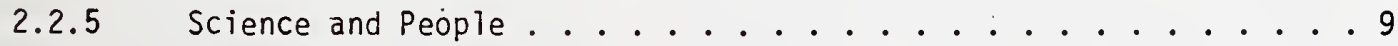

2.3 Realized Measurement Capabilities . . . . . . . . . . . 9

2.4 Dissemination and Enforcement Network . . . . . . . . . 9

2.5 Organization Input-Output Transactions Matrix .......... 10

3. IMPACT, STATUS AND TRENDS OF MEASUREMENT SYSTEM . . . . . . . . . 10

3.1 Impact of Measurement . . . . . . . . . . . . 10

3.2 Status and Trends of the System ................ 10

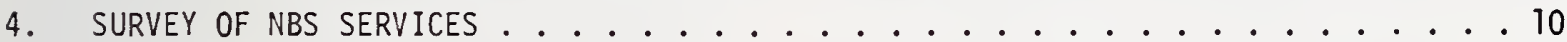

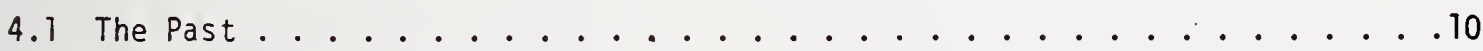

4.2 The Present -- Scope of NBS Services . . . . . . . . . . . . 10

4.2.1 Description of NBS Services .............. . . . . .

4.3 Impact of NBS Services . . . . . . . . . . . . . . 12

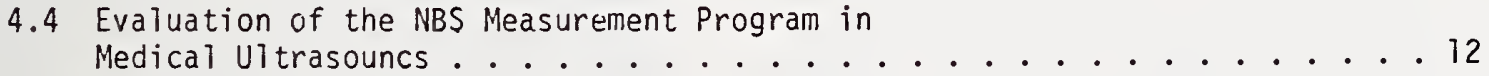

4.5 The Future -- Recommended NBS Actions . . . . . . . . . . 12

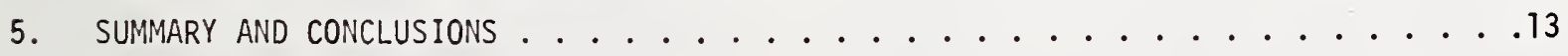

APPENDIX A. METHODOLOGY OF THE STUDY. . . . . . . . . . . . . . . . . . . . .

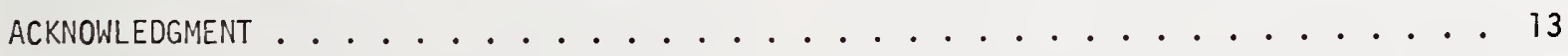

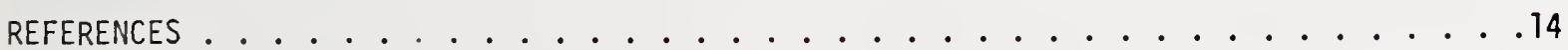


THE NATIONAL MEASUREMENT SYSTEM FOR MEDICAL ULTRASONICS

\author{
Paul A. Hudson \\ Electromagnetics Division \\ Institute for Basic Standards
}

February 1976

\begin{abstract}
The rapid increase in the use of ultrasonics in medical diagnostics has been brought about by recent advances in imaging techniques employing sophisticated electronic systems. Along with the proliferation of this equipment in the medical community has come concern about possible tissue damage due to this type of radiation. Research on damage thresholds is being carried out in laboratories across this country and overseas. Agreement between various researchers is hampered by lack of accurate standards for measurement of transducer beam power and intensity.

The National Measurement System for medical ultrasonics is, at this time, inadequate, fragmented and largely uncoordinated. The Electromagnetics Division is in process of developing standards for measurement of transducer beam power, intensity and beam pattern. These standards will be disseminated widely throughout the country to provide the needed accuracy and measurement agreement among biomedical researchers and ultimate users (hospitals, physicians, clinics, etc.). Interim standards for beam power were developed $11 / 2$ years ago and are already in use by standards laboratories of manufacturers and universities. It is estimated that another 5 years will be required to bring the measurement system under some form of control.
\end{abstract}

Key Words: Electroacoustics; medical diagnostics; radiation safety; radiation therapy (ultrasonic); ultrasonics. 
Paul A. Hudson

\author{
Electromagnetics Division \\ Institute for Basic Standards
}

\title{
February 1976
}

\section{EXECUTIVE SUPMARY}

The medical applications of ultrasonics have increased at a rapid rate during the past five years. Ultrasonics is used for diagnostics, therapy (diatherny) and surgery. The most important of these is the diagnostic applications. Recent advances in signal processing techniques and hardware have made possible the conversion of ultrasonic images to real-time optical images of good quality. Systems employing complex phased arrays of transducers are now in the laboratory stage and will find their way to the practitioner within the next two years. A large amount of activity is going on in these developments in university laboratories, manufacturers, and non-profit organizations. The size of the field of medical ultrasonics is estimated to be between 550\% and SioOM. These figures include doctor's fees, research and equipment production. Projections by knowledgable people indicate that by 1985 sales of ultrasonic diagnostic instruments will equal or exceed saies of X-ray equipment.

Reviews of the literature have uncovered a considerable concern with regard to the toxicity of uitrasonic waves on certain parts of the body. Since ultrasonics is widely used in fetal studies, a large amount of the concern was in this area. Certain consumer groups (e.g., Ralph Nader) have testified before congressional committees detailing their concern over this new medical tool.

Research into the toxic effects and damage thresholds of ultrasonic radiation are in progress. However, it is expected to require several years before definitive, quantitative results are obtained. In the meantime, measurements are hampered by a lack of standards and measurement consistency between various researchers.

The National Measurernent System as it applies to medical ultrasonics is fragmented, uncoordinated and inadequate. Measurement capability for the more important parameters, power, intensity, and beam pattern, is mostly centered in development laboratories, certain manufacturers, and government laboratories. The
Bureau of Radiological Health (DHEW/FDA) maintains measurement capability designed to aid in their role as the regulatory agency under provisions of the Radiation Health and Safety Act of 1968. The Electromagnetics Division of NBS began standards development three years ago and now offers a limited calibration service at 1 , 2, 3 and $5 \mathrm{MHz}$ for total beam power. Also offered is a measurement service for efficiency of high-Q quartz transducers in the band 0.5 to $10 \mathrm{iHz}$. Accuracies at NBS are $5 \%$ or better as compared to $10 \%$ to $30 \%$ in the field. A serious hindrance to more widespread standards dissemination is the lack of a suitable transfer standard device. It is believed that a low-cost, rugged and reliable device can be developed for use by both technical and non-technical (medical) personnel.

Vlational laboratories in foreign countries, notably West Germany and Australia, have developed standards for important ultrasonic quantities and offer a more complete measurement service than does NBS at this time. At the PTB in West Germany, for example, the ultrasonics group consists of 15 people and they have been working in the field for more than 12 years.

As a result of announcement of NBS services (August, 1974), numerous inquires have been received, calibrations have been performed, and negotiations are in progress for intercomparisons with two leading university laboratories. Intercomparisons with BRH have been carried out. This was important to that agency in that they were able to proceed with the preparation of regulatory documents. Information received at NBS indicates that these documents will prescribe that all ultrasonic medical equipment be metered for power output and that the accuracy of the metering be within certain limits. This is expected to create a demand for NBS measurement services from manufacturers who wish to insure that their equipment meets BRH requirements.

Close cooperation and exchange of information is maintained between NBS and BRH. For example, information gained by BRH in their field surveys and contacts with manufacturers is passed on to NBS. The BRH 
program in ultrasonics standards is aimed at development of working standards for use in their regulatory role. They look to NBS for development and maintenance of basic standards.

For the future, the Electromagnetics Division has under development a precision scanning system (computer controlled) to yield accurate measurements of field and beam patterns of ultrasonic transducers and arrays. This system is expected to become a major factor in solving measurement problems which now exist. A new calorimeter which is to serve as a basic standard for power measurement, is nearing completion. Thus, the potential impact of NBS on the important field of medical ultrasonics appears to be substantial. 


\section{INTRODUCTION}

U1trasonic techniques are becoming increasingly important in medical applications including diagnosis, therapy and surgery. In diagnosis, for example, ultrasonic techniques are gaining ever greater acceptance by radiologists as a unique diagnostic modality that complements and is often superior to medical procedures involving the use of ionizing radiation (1). Each day ultrasound is in routine clinical use in hospitals and medical centers throughout the world for the diagnosis and treatment of such diverse soft-tissue structures as the brain, heart, liver, kidneys, breast, the reproductive systems, the vascular system, the fetus and the eye (2).

Because ultrasound may be used noninvasively, it is a nearly ideal tool for the study of blood flow and valve function in the larger vessels (e.g., by means of doppler and pulsed doppler techniques) and for observing the motion and character of organs (e.g., by pulse-echo mapping with mechanically scanned systems or phased arrays, by the use of doppler techniques and by systems based upon holographic principles).. As one doctor put it, .... Once these machines come out of the laboratory and are put to use in screening for circulatory disease, there is a good chance that we can decrease the death rate from this type of disease by $30 \%$.

The hazards associated with ultrasonic radiation are the subject of continuing research, (although it is generally conceded that ultrasonic diagnosis at conservative power levels is safer) than diagnosis by means of ionizing radiation, where the results of genetic damage can often be severe. A recent survey by the Bureau of Radiological Health indicates that at present, fetal scans are performed on approximately $35 \%$ of pregnant women in the United States. This percentage is expected to increase in the future as improved imaging techniques come into use.

Much of the present impetus for characterization of the acoustic fields of transducers and for precise and convenient measurements of acoustic field quantities comes from researchers engaged in the assessment of the effects of ultrasound upon tissue. However, the present proliferation, in number and kind, of commercial ultrasonic equipment suggests the necessity and inevitability of controls by government regulator agencies. This, in turn, implies an even greater suture need for precise and convenient methods for measuring the fields of medical transducers.
Those dealing with ultrasound hazards are faced with a difficult problem. It is not generally possible for measurement to be made in vivo and therefore measurements of ultrasonic quantities are typically made in water tanks. The problem thus remains of relating these measurements to the complex propagation phenomena that occur in tissue. Little work has been done in defining the relative roles of phenomena such as scattering and relaxation effects upon sound propagation (e.g., upon sound speed and attenuation) in tissue. Thus, good basic experimental and theoretical work is most urgently needed in this area.

Historically, the clinical applications of ultrasound date back to the 1930's. For a time, improvement of the early systems was slow and their acceptance was rot widespread. This was because valid results required highly trained technicians. Therefore, results often appeared to have a subjective quality. In more recent years, the advent of solid-state technology, microcircuits and information processing techniques has resulted in improvements which permit relatively unskilled personnel to obtain good results.

Many of the more advanced systems (e.g., the more sophisticated phased array instrumentation) are currently undergoing development or preliminary clinical evaluation. However, the Federal Government has provided $\$ 3$ million to the National Science Foundation to accelerate refinements and provide more rapid availability of equipment to hospitals and other users. Thus, there appears to be little doubt that the medical applications of ultrasound will increase rather rapidly. Indeed, some have predicted a boom to the extent that uses of ultrasound will equal or exceed X-rays within ten years $(3)(4)$.

\section{STRUCTURE OF THE MEASUREMENT SYSTEM}

\subsection{Conceptual System}

In medical applications of ultrasonics, mechanical waves at ultrasonic frequencies are transmitted as a beam through body tissue for therapeutic purposes, or to obtain information on soft tissue structures, or to destroy a region of tissue. To obtain the desired effect without toxicity, users of ultrasonic equipment generally are most interested in the power, the intensity (power per unit area), and the field pattern (intensity as a function of location in the field) of the ultrasonic 
radiation. For specific needs, there is often an interest in acoustic pressure, particle velocity, sound speed, absorption (i.e., conversion to heat), attenuation, and transducer efficiency. Another quantity of interest is the specific acoustic impedance to plane waves in the medium.

lable 1 shows the most important quantities used in medical ultrasonics, the quantity symbol, and the appropriate SI units.

Physical laws provide relationships among these measurement quantities. For example, for plane waves the acoustic intensity (power per unit area) is related to acoustic pressure, particle velocity, and specific acoustic impedance by the simple algebraic formula $I=P / S=p u=$ $u^{2} \rho_{0} c=p^{2} / \rho_{0} c$. However, in the near

field of an ultrasonic transducer, wherein most medical applications lie, such planewave relations are not appropriate. The field quantities are most accurately defined and measured using methods that properly account for the complex structure in the near field of ultrasonic beams.
Field quantities most of ten of interest are intensity at a specified point in the field, total beam power, acoustic pressure, and field pattern. Methods exist for determining these quantities in terms of other measurable quantities.

Intensity and acoustic pressure are usually measured with a small piezoelectric, capacitive or thermal probe previously calibrated in a field of known intensity of pressure, or by using a very small target as a sensor of radiation pressure. Beam power is often measured with radiation force devices, or with calorimetric devices, or with acousto-optic equipment. The field pattern of a transducer is usually measured with a probe mounted on a precision scanning mechanism. A laseracoustic scanning system now under development (by RCA) (5) will measure displacement amplitude. A precision scanning system under construction (by NBS-Boulder) will be used to provide probe-corrected information on nearly all field quantities, based on a plane wave scattering matrix (PWSM) formulation developed at NBS (6).

Table 1. Symbols and SI Units for Ultrasonic Quantities.

\begin{tabular}{|c|c|c|}
\hline Quantity & $\begin{array}{l}\text { Quantity } \\
\text { Symbol }\end{array}$ & $\begin{array}{l}\text { SI Unit } \\
\text { (Symbol) }\end{array}$ \\
\hline Particle displacement & $y$ & m \\
\hline Particle velocity (vector) & $\underline{u}$ & $m \cdot s^{-1}$ \\
\hline Speed of sound & c & $m \cdot s^{-1}$ \\
\hline Density & $\rho$ & $\mathrm{kg} \cdot \mathrm{m}^{-3}$ \\
\hline $\begin{array}{l}\text { Specific acoustic impedance } \\
\text { for progressive plane waves. } \\
\rho_{0} \text { is the equilibrium density }\end{array}$ & $\rho_{0} c$ & $\mathrm{~N} \cdot \mathrm{m}^{-3} \cdot \mathrm{s}=\mathrm{kg} \cdot \mathrm{m}^{-2} \cdot \mathrm{s}^{-1}$ \\
\hline Force & $\mathrm{F}$ & N \\
\hline Pressure & $P$ & $\mathrm{~Pa}=\mathrm{N} \cdot \mathrm{m}^{-2}$ \\
\hline Power & $P$ & W \\
\hline Intensity & I & $w \cdot m^{-2}$ \\
\hline $\begin{array}{l}\text { Amplitude attenuation } \\
\text { coefficient }\end{array}$ & $\propto$ & $\mathrm{Np} / \mathrm{m}$ \\
\hline Efficiency (transducer) & $n$ & dimensionless \\
\hline
\end{tabular}

Note: In the units column of the table above: $\mathrm{kg}=\mathrm{ki}$ logram, $\mathrm{m}=$ metre, $\mathrm{s}=$ second, $\mathrm{N}=$ newton, $\mathrm{Pa}=$ pascal, $\mathrm{W}=$ watt, $\mathrm{Np}=$ neper . 
The velocity of sound in, and density of, water are near that of soft tissue in the body, and water is commonly used as the convenient standard medium for evaluation of medical ultrasonic equipment. Sound speed and density information for water are available as reference data. Information on ultrasonic absorption and other forms of attenuation is obtainable for some, but not all, liquids and solids. Specific acoustic impedances for plane wave propagation in some materials are available as reference data, and the quantity can be calculated as the product of the density times the speed of sound in the material.

Several types of standard test objects have been described for use in checking resolution of ultrasonic diagnostic equipment. Most laboratories have constructed their own test objects, and at least one of these is now commercially available.

The only commercially-available measuring equipment for medical ultrasonic field quantities (e.g., power, intensity, pressure) are piezoelectric probes and radiation-force power meters. The latter are useful for power levels from about 5 to 25 watts. A number of laboratories in universities, hospitals, industry, and in government have built their own equipment to perform required measurements, often at great expense, and sometimes with uncertain results. A few interlaboratory intercomparisons have been carried out ( 7 ). Careful workers have attained uncertainties believed to be in the $\pm 5 \%$ to $\pm 15 \%$ range for the field quantities of power, intensity, and pressure. Uncertainties of $\pm 15 \%$ are not adequate for laboratories concerned with meeting and enforcing performance standards for ultrasonic equipment, yet, $\pm 5 \%$ uncertainties are difficult to achieve.

\subsection{Basic Technical Infrastructure}

\subsubsection{Documentary Specification System}

\subsubsection{Standardization Institutions}

Attempts by standardization organizations to establish uniform methods of measurement for power and intensity of therapeutic ultrasonic transducers date back 20 years or more. For example, the current standard was promulgated by the American Standards Association in 1956. This standard follows very closely that recommended by the International Electrotechnical Commission which is based upon techniques available in the 1950's.

As shown by the list below, a surprisingly large number of organizations are active in the standards area. Communication and coordination between these groups is needed and NBS is represented in at least three of the more important ones.

-- International

1. International Electrotechnical Commission

2. International Federation of Medical Ultrasonics

-- U.S. Government Legal and Regulatory

1. U.S. Dept. of Health, Education \& Welfare (HEW)

(a) Health Services and Mental Health Administration National Institute for Occupational Safety \& Health (NIOSH)

(b) Food and Drug Administration (FDA)

Bureau of Radiological Health (BRH)

2. U.S. Dept. of Labor

(a) Occupational Safety and Health Administration (OSHA)

-- U.S. Government - Non Regulatory Dept. of Comm. NBS/Dept. of Defense Veterans Administration

\section{-- Voluntary Standards Institutions}

1. American National Standards Institute (ANSI)

2. Institute of Electrical and Electronic Engineers, Inc. (IEEE)

3. Instrument Society of American (ISA)

4. Acoustical Society of America (ASA)

5. Association for the Advancement of Medical Instrumentation (AAMI)

6. American Society for Testing and Materials (ASTM)

7. American Institute for Ultrasound in Medicine (AIUM)

8. Alliance for Engineering in Medicine and Biology (AEMB) 
-- Other Standardizing and Measurement Institutions

1. Foreign

(a) Standards Association of Australia

(b) British Standards Institution

(c) Canadian

(d) Physikalisch-Technische Bundesanstalt

2.2.1.2 Survey of Voluntary (Documentary) Standards and Recommendations

I. American National Standards Institute

A. Sponsored by the Acoustical Society of America (ASA)

1. Procedures for Calibration of Underwater Electroacoustic Transducers. ANSI S1.20-1972

2. Acoustical Terminology (Including Mechanical Shock and Vibration) USAS S1.1-1960 (Revision of 224.1-1951 and Includes Z24.1a)

3. Specifications for Laboratory Standard Microphones USAS S1.12-1967 (Revision of 224.8-1949)

4. Method for Specifying the Characteristics of Analyzers Used for the Analysis of Sounds and Vibrations. USAS 224.15-1955

5. Calibration of Microphones. USAS S1.10-1966 (Revision of 224.4-1949 and 224.11-1954)

6. Calibration of Electroacoustic Transducers. USAS 224.24-1957. Sponsored by the Acoustical Society of America

7. U7trasonic Therapeutic Equipment. ASA Z24.18-1956

B. Sponsored by the Institute for Electrical and Electronic Engineers (IEEE)

1. Standard Definitions and Methods of Measurement for Piezoelectric Vibrators. ANSI C83.17-1970 (IEEE Na 177-1966)

2. IRE Standards on Piezoelectric Crystals: Determination of the Elastic, Piezoelectric and Dielectric Constants - The Electromechanical Coupling Factor, 1958 ANS I C83.23-1960 (IEEE Std. 178-1958, Reaffirmed 1971)
3. Standards on Piezoelectric Crystals, 1949 ANSI C83.3-1951 (Reaffirmed 1972) IEEE Std. 176-1949 (Reaffirmed 1971) SH-0106-5

4. IRE Standards on Piezoelectric Crystals: Measurements of Piezoelectric Ceramics, 1961 ANSI C83.24-7962 (Reaffirmed 1972) IEEE Std. 179-1961 (Reaffirmed 1971) SH-0109-9

C. Other Voluntary Standards and their Sponsor

1. IEEE Standard on Magnetostrictive Material: Piezomagnetic Nomenclature IEEE Std. 319-1971 SH-0236-0 Institute for Electrical \& Electronic Engineers

2. IRE Standards on Piezoelectric and Ferroelectric Crystals: Definitions of Ferroelectric Crystal Terms 196262 IRE 14.S1 SH-02527 Institute of Electrical \& Electronic Engineers

3. Specifications and Tests for Piezoelectric Pressure and Sound Pressure Transducers ISA-\$37.10 1969 Instrument Society of America

4. Specification and Tests for Piezoelectric Pressure and Sound Pressure Transducers ISA-S37.10 1969 Instrument Society of America

5. Testing and Calibration of U1trasonic Therapeutic Equipment Publication iso 1963 international Electrotechnical Commission

6. U1trasonic Therapeutic Equipment AST 40-1969 Standards Association of Australia

7. Standard Specifications of Echoscope Sensitivity and Noise Level Including Recommended Practice for Such Measurements Adopted October, 1973 American Institute of UTtrasound in Medicine 


\subsubsection{Measurement Tools and Techniques}

Within the past year at least three techniques have been reported in the literature for measurement of the near and far field characteristics of ultrasonic transducers in a water medium. These include two optical methods (3.9) and a steel ball reflector scheme (10) which employs conventional instrumentation. The data provided by these methods is mostly in terms of relative field intensity rather than absolute values. Nevertheless, the data does provice useful information concerning transducer quality.

Powerful techniques have oeen developed for the evaluation of sonar arrays and electromagnetic antennas. Although, these array and antenra problems are somewnat different than those in medical ultrasonics, they have served to suggest analogous methods of equal (and greater) utility for the evaluation of trarisducer-fluid systems empioying ultrasound.

Also, several methods for measuring acoustic field quantities have evolved to meet the needs of individual 7aboratories. Intercomparisons of techniques used by various laboratories have taken place. The present state of knowledge in this field is such that no single measurement system has ererced as a orimary steridard. It is possible that more flexible and perhaps less convenient methods of field specification (e.g., a cetermination requiring detailed scanning of the radiation field) may emerge as such a primary standard. It will then be possible to evaluate the performance of less flexible measurement systems and more precisely calibrate convenient secondary standards for dissemination to laboratories, hosoitals and medical centers.

The following paragraphs will outline existing tools and techniques in medical ultrasonics. These will include existing techniques for determining field quantities, field scanning and mapping technology, and instrumentation performance stanaaros.

\section{Field Scamning Wethodolocy and Equioment}

The necessary equipment for the mapoing of acoustic fields must include a positioning mechanis. with an inherent uncertainty in position that is a smali fraction of a wavelength, ars an "ideal" field probe. An ideal probe snould have a critical ditension that is a small fraction of a wavelength to prevent spatial averaging effects. It must also be neariy omnidirectional and nave a flat frequency response.
Wavelengths on the order of one millimeter are commonly used in medical ultrasound. For imaging eye structures the wavelengths may be less by a factor of ten or more. Thus, the requirement that the prode size be a small fraction of a wavelength imposes a serious fabrication problem. In addition probes having sucn a small size are generally very insensitive.

Recent work at NBS - Boulder has provided the theoretical basis and the means for correcting a known receiving probe for non-ideal characteristics. This solves the sensitivity and fabrication problems, because a larger probe may be used. The resulting data may then be corrected to that of an ideal, omidirectional, point probe having a flat frequency response. The basis of this work is a plane-wave scattering matrix (PWSil) formulation involving the relatively mild assumotions of 1 inearity, a homogeneous medium, and negligible secondary reflections. This work also allows more efficient scanning since a scan over a single plane (e.g., in the near field of a transducer) is shown to be sufficient for complete specification of the sound field.

Since errors due to the directional characteristics, spatial averaging effects, and irecuency response of a probe may be removed, the remaining errors for in-vitro measurements at diagnostic power levels should reside in the sampiing process and the precision of the traversing mechanism. These errors may be estimated and hence there is no conceptuai difficulty in making them arbitrarily small. Therefore, efficient scanning employing a PUSil formulation has the potential of being a more precise, possibly primary, measurement system for medical diagnostic transducers.

\section{Existing Methods of UItrasonic Field
Measurement}

At this time the following techniques are being examined and used for measuring quantities in the acoustic fields of medical transducers. There is no current agreement concerning the relative suderiority of any one of these techniques. In fact, there has been no definitive work outlining the sensitivity of these methods over ranges of e.g., acoustic power, acoustic intensity, or frequency. In at least some cases, this information is not yet known. 
However, it seems certain that some combination of these methods will provide the basis for a convenient system of primary or secondary standards for the specification of the important field quantities associated with the diverse and expanding

field of medical ultrasonic equipment.

These methods are:

1. Radiation Force Measurements -- field quantities are determined by observing the deflection of a reflecting or absorbing target in the acoustic field.

2. Calorimetry -- field quantities are determined from observation of the temperature rise in the fluid due to sound absorption.

3. Methods Involving Capacitive Transducers -- field quantities are determined from the modulation of the spacing of a charged parallel plate capacitor by and incident sound wave.

4. Methods Involving Reciprocity Calibration Techniques -- field quantities are determined using the field-theoretic principle of reciprocity. For example, the measurement could involve two identical transducers, or three transducers, one of which is known to be reciprocal. This technique has involved far-field relationships.

5. Optical Diffraction Techniques -- field quantities are determined from the diffration of light by the acoustic field.

6. The Electrical or Equivalent Circuit Method -- evaluation of the parameters in an equivalent circuit model of resonant transducers under different loacing conditions permits determination of the radiated power directly from electrical measurements.

\section{Instrumentation Performance Standards}

Recently, the American Institute of U7trasound in Medicine adopted a standard test object (i.e., a wire gauge for use in tanks of fluid) for the clinical evaluation of azimuthal and range resolution provided by diagnostic pulse-echo equipment. Consideration has been given by the AIUM standards committee to tissue phantoms, which would help in the evaluation of an ultrasonic system's ability to discriminate between soft tissue structures. However, this idea has been set aside for the present because not enough is known about both sound propagation in tissue and the stability of the acoustical properties of polymers over extended time periods.
The method is more qualitative than quantitative. With the advent of, for example, phased array instrumentation involving signal processing, compression of the dynamic range of echo-information, the use of switched delay lines, and gray-scale CRT displays, evaluation of resolution characteristics alone is overly simplistic and inadequate.

Other groups, such as the Acoustical Society of America and the International Electrotechnical Commission, are working on the development of performance standards for ultrasound diagnostic equipment.

\subsubsection{The Instrumentation Industry}

One of the clearest pictures to emerge as a result of this study is the nonavailability from commercial sources of accurate, reliable ultrasonic measurement equipment. At present there are less than a dozen companies which make measuring instruments and such equipment is usually a sideline. The performance characteristics of available instruments have not been evaluated at NBS so that we are unable at this time to assess their adequacy. However, as a result of conversations with colleagues and perusal of the literatire, it appears that present instruments leave something to be desired in the way of accuracy, reliability, and user convenience.

At least three manufacturers of ultrasonic equipment are now attempting to manufacture ultrasonic power measurement equipment. As of this writing their instruments have not appeared on the market. Doubtless, more manufacturers wi 11 enter the field as measurement needs become more acute with the growth in numbers of ultrasonic equipment users.

At present, manufacturers do not maintain traceability for ultrasonic power and intensity to national reference standards. Within the next year, NBS will attempt to estabiish a Measurement Assurance Program (MAP) with manufacturers of both measuring instruments and medical ultrasonic equipment. The new $B R H$ regulation on therapeutic equipment is expected to be issued very soon. This regulation is expected to be a strong incentive for manufacturers to seek traceability to national standards. We believe that they will welcome any help that they can get to insure that equipment meets $\mathrm{BRH}$ requirements. 


\subsubsection{Science and People}

The professional societies relevant to this field of measurement activity and their interrelationship are as follows:

\section{International Electrotechnical Commission}

Technical Committee on Electroacoustics Sub-Committee 29D: U1trasonics Working Group 4: Medical Applications

Alliance for Engineering in Medicine and Biology (AEMB)

AEMB's Professional Society Membership includes the following organizations:

1. Aerospace Hedical Association

2. American Academy of Orthopedic Surgeons

3. American Association of Physicists in Medicine

4. American College of Chest Physicians

5. American College of Physicians

6. American College of Radiology

7. American College of Surgeons

8. American Institute of Aeronautics and Astronautics

9. American Institute of Biological Sciences

*10. American Institute of U1trasonics in Medicine

11. American Society for Engineering Education

12. American Society for Heating, Refrig. \& Air-Cond. Engineers

13. American Society for Hospital Engineers of Am. Hosp. Assoc.

*14. American Society for Testing and Materials

15. American Society of Agricultural Engineers

16. American Society of Internal Medicine

17. American Society of Mechanical Engineers

*18. Association for the Advancement of Medical Instrumentation

*19. Biomedical Engineering Society

*20. Institute of Electrical and Electronic Engineers

21. Instrumentation Society of America

22. National Associations of Bioengineers

23. Neuroelectric Society

24. Society for Advanced :ledical Sys tems

*Organizations which have standards committees

\subsection{Realized Measurement Capabilities}

Existing measurement capabilities for ultrasonic power and intensity are located mostly in university laboratories (many of which are associated with medical schools), certain manufacturers, research hospitals, the Bureau of Radiological Health (BRH), and at NBS. Much of this capability (outside BRH and NBS) is specialized for particular applications and little if any capability exists in treatment hospitals and clinics.

In a recent (1973) survey in Dada County, Florida, and Montgomery County, Maryland, the BRH found that the sonic output of therapeutic transducers differed by as much as 100\% compared to the reading of the meter contained in the equipment. In one case, a therapeutic transducer used almost daily by a certain hospital was found to have no output even though the internal meter indicated normal operation.

These examples serve to illustrate the chaotic conditions which presently exist in parts of the medical ultrasonics field.

Table 2 below shows the measurement capability in various segments of the measurement system.

Table 2. Capability in Various Segments of the Measurement System.
Segment

NBS

BRH

Research Hospitals

Manufacturers

Treatment Hospitals

Clinics
Capability (accuracy)

$3 \%$ to $5 \%$

$5 \%$

$10 \%$ to $15 \%$

$20 \%$ to $30 \%$

none

none

\subsection{Dissemination and Enforcement Network}

The Bureau of Radiological Health (BRH) has responsibility under the Radiation Control for Health and Safety Act of 1968 for enforcement of maximum radiated power and intensity rules which have yet to be adopted. For diagnostic equipment users have generally agreed upon :!pper limits for radiated intensity of $0.5 \mathrm{~mW} / \mathrm{cm}^{2}$ time averaged or $0.5 \mathrm{~W} / \mathrm{cm}^{2}$ peak pulse. 
The BRH maintains in-house standards for accurate measurement of the output power of medical ultrasonic equipment submitted to their laboratory for approval. They have no intention of disseminating standards or calibrating measuring equipment for other organizations. Therefore, it will be the responsibility of NBS to provide dissemination services as the first step in realizing a coherent measurement system. A major shortcoming of the present system is lack of a suitable transfer standard.

\subsection{Organization Input-Output Transactions Matrix}

The organizations which perform measurements include the BRH, university laboratories, manufacturers and users such as researchers and hospitals. Results of researchers investigating the biological effects of ultrasound are not always in agreement and one cause of this is the inaccuracies in measuring ultrasonic power and intensity at various laboratories. Users of ultrasonic equipment (i.e., hospitals and clinics) also make measurements of power especially for therapeutic applications. In addition to inadequate instrumentation, a large part of the problem also lies in the lack of knowledge of proper measurement techniques by medical personnel. Thus, a great amount of work must be done in the development of both standard techniques and their dissemination.

Measurement results are used by researchers in, for example, assessing the thresholds of tissue damage in animals and for other uses. Manufacturers require measurement results to establish specifications for their equipment and instruments sold in the marketplace. Periodic measurements are required in hospitals, etc., to insure the continued proper operation of ultrasonic equipment. The results of the surveys in Florida and Maryland, described above, are an example of what can happen when frequent monitoring is not carried out.

\section{IMPACT, STATUS AND TRENDS OF MEASUREMENT SYSTEM}

\subsection{Impact of Measurement}

The maximum allowable error in the power output metering for various types of medical ultrasonic equipment will be set by the BRH. Thus, every manufacturer and user will need accurate measurements to insure that equipment metering indications are operating within the established limits of error. In research on tissue damage by ultrasonics, it will be necessary that all measurements of power and intensity be referred to a common standard if observed damage levels are to correlate between researchers.

In therapeutic applications of ultrasound, different power levels are required to treat different parts of the body.

Therefore, accurate metering of the output power is important if expected results are to be obtained.

\subsection{Status and Trends of the System}

As stated previously, the present status of the system is fragmented, uncoordinated and inadequate. A serious shortcoming is the lack of a reliable, low-cost transfer standard which can be used by nontechnical personnel.

The trend is toward increasing demand for both quantity and quality of measurements from all segments of the industry, researchers and medical users. Two brief news releases from NBS during 1974 resulted in a large number (60) of inquiries from the field for more information, literature, etc. This is indicative of the increased interest in the measurement aspect of medical ul trasound.

At least three manufacturers have, in the past year, begun development of instruments to measure ultrasonic power. None of these are in production as yet and when they become available, they will be the first U.S. made instruments to come on the market.

Scanning systems are available commercially for measurement of ultrasonic beam profile and field pattern. The accuracy of these systems is not known at this time.

\section{SURVEY OF NBS SERVICES}

\subsection{The Past}

The Electromagnetics Division began development of standards for ultrasonic power in 1972. First announced services at $2 \mathrm{MHz}$ came in January, 1974, with additional frequencies, 1,3 and $5 \mathrm{MHz}$ in August, 1974. In addition, a 6 volume set of bibliography on ultrasonics was published and widely distributed.

\subsection{The Present -- Scope of NBS Services}

\subsubsection{Description of NBS Services}

Present NBS services include the measurement of the response of ultrasonic total beam power measuring instrument to inputs of known level in the range $5 \mu \mathrm{W}$ to $1 \mathrm{~W}$, 
continuous wave. The known power is emitted from NBS-characterized quartz transducers and the applied voltage is measured by NBS calibrated voltmeters. An overall accuracy of $5 \%$ or less is achieved at frequencies of $1,2,3$ and $5 \mathrm{MHz}$. Maximum beam diameter is $2.5 \mathrm{~cm}$.

The NBS standard is transportable and may be taken to customer sites for calibrating of measuring equipment.

The resonant radiation conductance, $\mathrm{Gr}$, of quartz transducers can also be measured at frequencies from 1 to $5 \mathrm{MHz}$. Such characterized quartz transducers could be used as a transfer standard by those laboratories which have the competence to make accurate high frequency voltage measurements and have other measuring equipment such as oscilloscopes.

Funding for NBS services will be on a reimbursable basis. Services will be provided by measurement of customer transducers or power measuring instruments at NBS or measurement of the response at power measuring instruments at the customer site.

The level of reimbursable funds for measurement services is expected to increase to $\$ 25 \mathrm{~K} / \mathrm{yr}$. by 1980 . Other agency funding for specific development projects will probably remain at the $\$ 20 \mathrm{~K}-\$ 30 \mathrm{~K}$ level.

Certain foreign national laboratories, notably West Germany and Australia, have been working on ultrasonic standards for some 15 years and have developed a larger capability in measurements than has NBS.

Because of the boom in commercial diagnostic equipment, a corresponding need is developing for measurement techniques to evaluate and regulate this equipment.

This need is five-fold. It includes:

1. A need for more precise measurements of pulsed acoustic fields, possibly representing a primary measurement system.

2. A need for more convenient secondary standards for dissemination to medical centers, hospitals and laboratories (government, industrial and academic).

3. A need for better evaluation and intercomparison of existing methods for measuring field quantities (especially more data on sensitivities as functions of acoustic power or intensity, and as functions of frequency).

4. A need for more precise relationships between in vivo acoustic propagation phenomena and their relation to in vitro (water tank) measurements.
5. A need for more and better test objects to provide performance standards for sophisticated medical ultrasonic equipment.

Work is currently underway at NBS-Boulder in areas 1,2 , and 3 .

\section{Area 1}

A scanning system and related theoretical work allowing probe correction and characterization shows promise of providing a precise (possibly a primary) measurement system. The theoretical work is largely complete for the acoustic case and the analogous electromagnetic formulation has been applied successfully in electromagnetic antenna calibration. The acoustical scanning system is currently under construction and an interim system may be complete in three months.

Area 2

This work is urgently needed and preliminary consideration is being given to the design of such secondary standards for field use.

\section{Area 3}

Efforts have been made to become aware of the technology and methodology currently in use in ultrasonics laboratories for evaluation of ultrasonic transducer-field systems.

A preliminary survey has been made of the ranges and types of balances applicable to the measurement of radiation force. Also, some understanding of the limitations of optical diffraction techniques has been gained. A theoretical generalization of reciprocity calibration techniques has been found which permits the determination at a single frequency of the directional character of each of three separate transducers from three transverse planar scans involving different pairs of the transducers.

\section{Areas $4 \& 5$}

No efforts, other than literature review, have taken place in these areas. However, expertise within the Electromagnetics Division (e.g., familiarity with scattering, lossy media and relaxation effects) could be brought to bear on problems of relating water-tank measurements to tissue properties. The experimental aspects of this work are probably beyond the scope of NBS-Boulder's activities. 
However, there is a strong possibility that a collaborative effort could be worked out with a medical center or academic laboratory.

Development and long-term evaluation of tissue phantoms would correlate well with the theoretical modeling of tissue properties.

\subsection{Impact of NBS Services}

There has not been adequate time to evaluate the impact of NBS services because the announcement of these services came only a few months ago. Nevertheless, inquiries by letter, telephone and at conferences indicate that the NBS services are most welcome and needed. Negotiations are in progress with two university laboratories for intercomparisons and/or calibrations of ultrasonic power measuring systems developed at the universities.

The major user classes include medical and biological researchers (e.g., university medical schools), manufacturers of equipment and instruments, regulatory agencies (i.e., BRH), and medical practitioners, hospitals, etc. The economic impact at this early date after announcement of NBS services is not known exactly but is believed to be small.

The technological impact is somewhat greater in that a new and independent standard was developed at NBS for calibration of ultrasonic power measuring equipment. The new standard utilizes existing electromagnetic standards to measure the resonant radiation conductance, $G_{r}$, of special quartz transducers. Ly measuring the input voltage to the transducer, the radiated acoustic power, $P$, is calculated from the equation $P=V^{2} G_{r}$. Details of this method have been disseminated via presentation of a conference paper, and subsequent publication in a widely circulated technical journal. Interest has been expressed by those in the measurement field to procure transducers similar to the NBS type and use them as transfer standards between NBS and their own laboratories.

\subsection{Evaluation of the NBS Measurement Program in Medical Ultrasonics}

In the three years of its existence, the NBS program in standards development for medical ultrasonics has made significant progress. The first step, a comprehensive literature survey, was published and disseminated to approximately 50 organizations and individuals. Subsequently, measurement standards were developed in the form of electrically characterized quartz transducers which serve as sources of known total beam power. These standards are especially useful for calibrating receivingtype transfer standards in a single measurement step. They were used in the 1973 intercomparisons with BRH.

Unfortunately, there exist but few receiving-type measuring instruments which are suitable as transfer standards. As mentioned previously, this fact is a major shortcoming in the effective operation of the NMS in medical ultrasonics. Present NBS capabilities are inadequate to meet present needs.

Additional capability nearing completion is the calorimetric type basic power standard developed with funding assistance from BRH. This standard will allow calibration of transducers directly. Also, the new scanning system for measurement of beam profile, power, intensity, etc., is $60 \%$ complete and will be usable in FY 76 .

With completion of these standards, NBS will have a well-rounded basic capability in ultrasonic power. The task of developing a low-cost, portable, reliable transfer standard will begin in late FY 76.

\subsection{The Future -- Recommended NBS Actions}

Since ultrasonics appears destined to become a major technology in medical diagnosis, it seems imperative that accurate standards for measurement of the physical quantities be provided by a competent government laboratory. NBS should be that laboratory.

There appears to be no authenticated instances of damage to human tissue under the conditions normally employed in diagnostic ultrasound. However, as usage expands and users strive for ever better sonic images, there will probably be a tendency to use higher intensities and longer exposure times. Thus, the establishment of danger threshold is a high priority necessity. A necessary tool in measuring damage thresholds is accurate standards for measurements of the levels of ultrasound which produce tissue damage. It is clearly an NBS function to provide an accurate consistent measurement system for ultrasound as has been done for other physical quantities and phenomena.

Within a year, NBS will have developed a new calorimetric power standard to supplement our present technique and a scanning system which will provide information on transducer field pattern, intensity distribution over the beam area and other quantities 
of interest. These systems are highly complex and require specialists for this proper operation. There needs to be developed simpler systems for use in the field. A very high priority item is development of a reliable, rugged, low-cost transfer standard for ultrasonic power so that NBS accuracy can be disseminated to users on the broadest possible basis. This transfer standard should be developed at NBS and subsequently manufactured by private industry.

Ul timately, NBS should provide a measurement assurance program in ultrasonics with manufacturers, BRH, and other principal laboratories such as universities and major medical centers. These latter laboratories could then provide measurement support to hospitals and other users.

To meet these objectives in a reasonable time the NBS level of effort should be increased to $\$ 250 \mathrm{~K}$ per year from the present $\$ 100 \mathrm{~K}$ per year for the next four to five years.

\section{SUMMARY AND CONCLUSIONS}

Diagnostic ultrasound is on the verge of a technological boom. To obtain maximum benefit from this technology and to protect the public from possible hazardous radiation levels, accurate standards must be developed and disseminated widely. NBS has developed standards for ultrasonic power at $1,2,3$, and $5 \mathrm{MHz}$. Standards for a much broader frequency range are in preparation and will be available in $i 976$.

The projected size of the medical ultrasonics field requires that NBS provide measurement services to include as a minimum, total power, intensity, field pattern, and transducer efficiency. Capability for accurate measurement of these quantities will form a basic national measurement system in ultrasonics and will be coordinated by NBS both in the U.S. and with foreign countries. Time-wise, the system is needed as soon as possible. Funding should be increased from the present level of $\$ 100 \mathrm{~K} /$ year to $\$ 250 k / y e a r$ for the next four or five years.
APPENDIX A.

This study is an updated revision of the U1trasound Issue Study performed in 1970-71. New information was gleaned from articles in technical journais, popular press, and conversations with other workers in the field. Many of the conversations, interviews, etc., are documented in trip reports from attendees at conferences, symposia, and meetings.

\section{ACKNOWLEDGMENT}

The following people contributed to the research and writing of this study:

T.L. Zapf
R.F. Metzker
Dr. Eric Miller

276.50

276.50

276 Postdoctoral Research Associate 


\section{REFERENCES}

[1] Erikson, K.R., Fry, F.J., and Jones, J.P., Ultrasound in medicine -a review, IEEE Trans. on Sonics and U] trasonics, Vol. SU-21, No. 3, July 1974, pp. 144-170.

[2] Jungen, Ronald K., Ultrasonics in medicine: strong; getting stronger, IEEE Spectrum, Vol. 11, No. 8, August 1974, pp. 62-66.

[3] Marx, Jean L., Diagnostic medicine: the coming ultrasonic boom, Science, Vol. 186, 18 October 1974, pp. 247250.

[4] Prospectives for ultrasonic imaging in medical diagnosis, National

Science Foundation Report, Washington, D.C., November 1973.

[5] Mezrich, R.S., Etzold, K.F., and Vilkomerson, D.H.R., Ultrasonovision, Paper C-2, IEEE UItrasonics Symposium 1974, Milwaukee, Wisc., November 1974.

[6] Kerns, D.M., Scattering-matrix description and near-field measurements of electroacoustic transducers, NBS Tech. Note 651 (1974). Also J.A.S.A. (in press).

[7] Breazeale, M.A., and Dunn, F., Comparison of methods for absolute calibration of ultrasonic fields, J. Acoust. Soc. Am., 55, No. 3, pp. 671-672 (1974).

[8] Cook. B.D., and Berlinghieri, J.C., Experimental mapping of ultrasonic fields by light diffraction, Proceeding 1975 IEEE Ultrasonics Symposium, pp. 133-135.

[9] Mezrich, R., Vilkomerson, D., and Elgod, E., Ultrasonic imaging exploits phase contrast, IEEE Spectrum, Vol. 12, No. 12, Decenber 1975, pp. 35-39.

[10] Cousin, A.J., Smith, K.C., and Rowe, I.H., A calibrated ultrasonic field measuring system for general use, IEEE Trans. on Instrumentation and Measurement, Vol. IM24, No. 4, December 1975, pp. 317-321. 
NBS.114A (REV. 7.73)

\begin{tabular}{|c|c|c|c|}
\hline $\begin{array}{l}\text { U.S. DEPT. OF COMM. } \\
\text { BIBLIOGRAPHIC DATA } \\
\text { SHEET }\end{array}$ & $\begin{array}{l}\text { I. PUABIK ATTON OR RI:PORT NO. } \\
\text { NBSIR } 75-937\end{array}$ & $\begin{array}{l}\text { 2. Gov't Accession } \\
\text { No. }\end{array}$ & 3. Recipient's Accession No. \\
\hline \multirow{2}{*}{\multicolumn{3}{|c|}{$\begin{array}{l}\text { 4. THTLE AND SUBTITI: } \\
\text { The National Measurement System for Medical Ultrasonics }\end{array}$}} & $\begin{array}{l}\text { 5. Publication Date } \\
\text { February } 1976\end{array}$ \\
\hline & & & $\begin{array}{l}\text { 6. Performing Organization Code } \\
276.02\end{array}$ \\
\hline \multicolumn{3}{|l|}{$\begin{array}{l}\text { 7. AUTHOR(S) } \\
\text { PauT A. Hudson }\end{array}$} & 8. Performing Organ. Report No. \\
\hline \multirow{2}{*}{\multicolumn{3}{|c|}{$\begin{array}{l}\text { 9. PERFORIING ORGANIZATION NAME AND ADDRESS } \\
\text { NATIONAL BUREAU OF STANDARDS } \\
\text { DEPARTMENT OF COMMERCE } \\
\text { WASHINGTON, D.C. } 20234\end{array}$}} & $\begin{array}{l}\text { 10. Project/Task/Work Unit No. } \\
2762111\end{array}$ \\
\hline & & & 11. Contract/Grant No. \\
\hline \multirow{2}{*}{\multicolumn{3}{|c|}{ 12. Sponsoring Organization Name and Complete Address (Street, City, State, ZIP) }} & $\begin{array}{l}\text { 13. Type of Report \& Period } \\
\text { Covered }\end{array}$ \\
\hline & & & 14. Sponsoring Agency Code \\
\hline
\end{tabular}

15. SUPPIEMENTARY NOTES

16. ABSTRACT (A 200-word or less factual summary of most significant information. If document includes a significant bibliography or literature survey, mention it here.)

The rapid increase in the use of ultrasonics in medical diagnostics has been brought about by recent advances in imaging techniques employing sophisticated electronic systems. Along with the proliferation of this equipment in the medical community has come concern about possible tissue damage due to this type of radiation. Research on damage thresholds is being carried out in laboratories across this country and overseas. Agreement between various researchers is hampered by lack of accurate standards for measurement of transducer beam power and intensity.

The National Measurement System for medical ultrasonics is, at this time, inadequate, fragmented and iargely uncoordinated. The Electromagnetics Division is in process of developing standards for measurement of transducer beam power, intensity, and beam pattern. These standards will be disseminated widely throughout the country to provide the needed accuracy and measurement agreement among biomedical researchers and ultimate users (hospitals, physicians, clinics, etc.). Interim standards for beam power were developed $11 / 2$ years ago and are aiready in use by standards laboratories of manufacturers and universities. It is estimated that another 5 years will be required to bring the measurement system under some form of control.

17. KEY WORDS (six to twelve entries: alphabetical order; capitalize only the first letter of the first key word unless a proper name; separated by semicolons)

Electroacoustics; medical diagnostics; radiation safety; radiation therapy (ultrasonic); ultrasonics.

\begin{tabular}{|c|c|c|}
\hline $\begin{array}{l}\text { 18. Al'AILABILITY Unlimited } \\
\text { DX For Official Distribution. Do Not Release to NTIS }\end{array}$ & $\begin{array}{l}\text { 19. SECURITY CL.ASS } \\
\text { (THIS REPORT) } \\
\text { UNCL ASSIFIED }\end{array}$ & 21. NO. OF PAGES \\
\hline 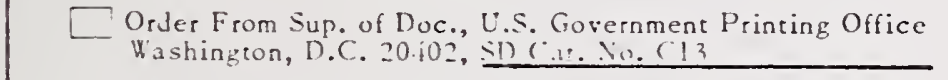 & $\begin{array}{l}\text { 20. SECURITY CLASS } \\
\text { (TIIIS PAGE) }\end{array}$ & 22. Price \\
\hline $\begin{array}{l}\text { Order Fom National Technical Information Service (NTIS) } \\
\text { Springfield, Virginia } 22151\end{array}$ & UNCLASSIIEIED & \\
\hline
\end{tabular}





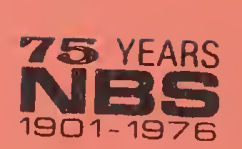

